\title{
Biology, Business and Brain Science: The Strangest of Attractors?
}

\author{
Raymond L. Forbes Jr. \\ Chair, MS in Business Psychology \\ Franklin University \\ Andy Igonor \\ Dean, Ross School of Business \\ Franklin University \\ Kody F. Kuehnl \\ Dean, College of Arts, Sciences and Technology \\ Franklin University
}

\begin{abstract}
The fields of biology, business and brain science seem headed down a path toward either collision or convergence. Although neither ordained nor inevitable, the growing interconnections of the three fields, like a snowball going downhill, appear to be currently gaining both momentum and magnitude. The implications of such a coming together are likely to be the subject of intensified debate and controversy among many of the affected parties well into the near-term future. Written from the perspective of practitioners and academics representing each of the three disciplines, this paper employs the concept of "strange attractor" from chaos theory as an integrating feature. This work will discuss several of the salient characteristics and principles existing within the fields of biology, business and brain science. It will also examine the gathering forces moving toward a furthered combination of the disciplines, examine enriched associations between them, and consider possible advantages and disadvantages of their linkages. Additionally, it will explore the possibilities inherent in their greater inter-disciplinary connections as well as peer into the darker side of an enhanced relationship.
\end{abstract}

Key Words: Biology; Business; Brain Science; Strange Attractors

INTRODUCTION

So, how did we get to this particular juncture in time where three seemingly independent and diverse fields like biology, business and brain science begin to be mentioned in the same breath? Where is the heightened interest coming from? What indicators are there that might lead us to think, like Sir Arthur Conan Doyle's fictional detective Sherlock Holmes, that "the game is afoot"? And, by the way, just what is a "Strange Attractor" anyhow?

Curiosity about a confluence of the fields is driven, in part, by projections of the possible advantages that might ensue from their confederation. Some of these benefits include: a broadening of perspectives, cross-pollination of ideas, a reduction in misunderstandings across disciplines, resource sharing, and efficiencies from elimination of duplication of efforts.

Underlying the growth of the fields of biology, business and brain science are a set of related technological, economic and social factors. These influences include advances fueled by 
computation, communications, materials sciences, artificial intelligence, and heightened knowledge of complex systems. Sample indicators of interest encompass: the increased frequency of public television programing on the topic, the number of presentations at academic conferences, blogs on the internet, and intensified mentions in the popular press.

The notion of a "strange attractor" comes from the discipline of complexity science. This specialty was first popularized in the late 1980s with the publication of James Gleick's book Chaos (1987). Gleick chronicled the efforts of Edward Lorenz to understand unpredictable weather patterns, mathematician Benoit Mandlebrot's work on fractals in mathematics, and Mitchell Feigenbaum's creative nature and art calculations. Together these individuals helped create an innovative geometry of the natural world that became the foundation for the new science of Chaos. At a more mundane human level, social psychologist Robert Cialdini suggests three naturally occurring attractors: the sexual, the threatening, and the different. (Cialdini, 2016).

Applications of Chaos theory continue to serve to blur and meander across the lines that separate scientific disciplines. Today, functioning as the world headquarters for complexity science, the Santa Fe Institute serves to perpetuate chaos theory. Located in Santa Fe, New Mexico, the institute operates as an independent, not-for-profit research organization that attracts complexity scholars from around the world.

Currently, within the domain of chaos theory, there are a number of conflicting definitions of the term "strange attractor." For purposes of this commentary, we will use author Ralph Kilman's definition from his book Quantum Organizations (2001). "Basically, a strange attractor is a rhythmic wave pattern that emerges from recurring particle locationsequivalent to a diagram of the quantum dance of a honeybee. Especially relevant, a strange attractor that emanates in the mind /brain is a multidimensional image of a meaningful thought category, or paradigm." In simple terms, a strange attractor is a repetitive, relatively stable pattern that occurs inside of surrounding conditions of disorder. Strange attractors show up as virtual islands of constancy within otherwise chaotic circumstances. Within the realm of brain science, strange attractors are believed to facilitate the hard-wiring, storage and recall of new neural structures and networks in the brain.

\section{NEW ENTICEMENTS FROM BIOLOGY}

One of the most dynamic, enticing and controversial areas of research within the field of biology today is the study of genomics. Genomics, broadly defined, deals with the complete set of DNA within a cell or organism and often the systematic study of the protein, RNA and metabolic products. The origins of genomics can be traced to 2003 with the complete mapping of a composite human genome by the Human Genome Research Institute. Amazingly, the field is producing and accumulating data at an astounding rate, the amount doubling every 7 months (Stephens et al. 2015). Some authorities even propose that, within the next decade, 1 in 7 people will have had their genomes sequenced or evaluated.

One result of this prodigious sequencing effort is that genomic data will likely soon represent the largest single segment of digital information in the entire world. The political, economic, and social ramifications surrounding the production of so much data, both from a data storage as well as from a data analysis perspective, are likely to be massive. On the positive side, with so much data at our fingertips, humankind appears to be on the precipice of having significantly greater knowledge about what makes us who we are as well as those factors that prevent us from being less than we could be. 
The relief or amelioration of crippling and life threatening disease has been a particular focus of genomic research. Many studies have shown that faulty or malfunctioning genes are implicated in many major debilitating diseases (e.g., cancer, cardiovascular disease, diabetes). For example, genomic research has allowed us to assess cancer at the molecular level so that we not only have the ability to diagnose it sooner, but we now can understand how cancerous cells develop and spread on an individual-by-individual basis.

In the arena of neurological and mental illness, genomic information is providing an unparalleled opportunity for earlier detection and more precise diagnoses. For example, the analysis of genetic data is exposing genetic predispositions associated with addictive (e.g., alcoholism, gambling) and potentially dangerous behaviors (e.g., suicide). Because mental illnesses and neurological disorders are often so complex, typically associated with hundreds of risk factors, genomics offers a means to identify the responsible genes, determine how and why they are malfunctioning, and provide the basis for new and more effective remedies.

Additionally, as a direct consequence of genetic research, the days of broad-based and often painful toxic treatment strategies (e.g., chemotherapies) are gradually being replaced with more effective individualized targeted treatments. Many of these new therapies are grounded in the sub-field of epigenetics. Epigenetic research, or the influence of the environment on which particular genes are turned on or off, has shown us that some critical human illnesses (e.g., cancer) are not the result of actual changes in the DNA sequence. These disabling maladies appear to be the consequence of changes in particular gene activity that can be influenced by a wide variety of ecological and environmental factors.

Genomics has also enabled breakthroughs in the application of biological algorithms, DNAbased computing, genomic editing, and xenotransplantation (i.e., transplantation of human cells, tissues, or organs grown from a nonhuman animal source). Besides its scientific, technological and social considerations, genomics is becoming big business. It has been estimated that the annual revenues from the genome sequencing and services market will soon be in excess of $\$ 20$ Billion. Many of the leading companies in this marketplace, such as 23 and me and AncestryDNA focus on targeting the individual consumer by providing medically or socially valuable information.

Advances in biological research also raise the scary specter of human-directed evolution. A stark negative portrayal of this possibility was depicted in 1997 with the release of the motion picture, Gattaca. This film pictured a world where genetic selection and genetic engineering (i.e., eugenics) formed the basis for an individual's future role in society. Society was set up such that there were a small group of haves and a vast majority of have-nots. Those with the preferred genetic traits were provided opportunities and special treatment unavailable to the preponderance of the populace who did not possess them.

The long-term ramifications of self-directed evolution are, with our present knowledge base, immensely difficult to predict. What will society do if this currently inchoate potential actually comes to fruition? If the contemporary assessment services provided by some commercial genomics companies are any indicator of the future (e.g., athletic ability, matchmaking, child talent), we may be headed into an ethical minefield. While the prospects of being able to identify all of the genetic predispositions of a fetus (e.g., designer babies) are likely years away, one of the present concerns that is becoming increasingly important is how we handle the associated risk information. 
However, the associated fear of directed-evolution and the misuse of genomic information is becoming palpable. For example, the US Food and Drug Administration has issued warnings to some for-profit companies regarding their intended use and interpretation of the findings of genomic testing, particularly focusing on the release of inaccurate results. The widespread availability of genomic information might also lead to poorer lifestyle decisions, particularly those related to the value of diet and exercise in health maintenance. Of possible equal concern is the observation that the availability of genetic information favors the rich to the detriment of the poor, which might lead to further socioeconomic disparity. One of the apparent lessons from Gattaca is that we, as a society, need to be more concerned about reaching a point where we have "discrimination down to a science" (DeVito et al, 1997). Will the focus on and promotion of subtle human genomic differences further aggravate our preexisting negative societal tendencies?

\section{THE PROMISE OF BUSINESS LEADERSHIP}

From the notable work of Psychologist Daniel Goleman (1998) on "social intelligence and leadership" to Tyagarajan's (2017) popular LinkedIn commentary on curiosity and innovation, society is today beguiled more than ever about what sometimes appears to be a mysterious connection between the brain and business. Even more enthralling is the interconnectedness between business enablers: technology, processes and people. Today's successful leader needs to understand how to influence people, technology and processes considering these are necessary for the engine of business.

Interestingly, dominant influences related to leadership, curiosity and innovation, as well as the obvious first impression linked to countenance and behavior can be traced back to biological origins. One of the pertinent questions worth answering is: "to what extent does biology influence business through leadership?" Research and experience point to individual differentiating biological traits apparent in cognition, behavior, communication, storytelling, curiosity and creativity. These traits appear to distinguish successful leaders in the world of business.

One of many definitions of leadership describes it as "one's ability to influence". John C. Maxwell asserts that the "true measure of leadership is influence - nothing more, nothing less". Yet, a key attribute of leadership is intuition; which according to Maxwell, "leaders seek to recognize and influence intangibles such as energy, morale, timing and momentum". The question then is - do you learn to be intuitive or are you born with this trait? This attribute can indeed separate a strong from a weak leader. An intuitive leader is often discerning, paying attention to the not-so-obvious characteristics, including body language in a work setting, and knowing how to quickly respond and change the setting. According to David Berreby (2010), "changing the way that companies operate is, at root, changing the way employees behave and think". If anything, this complicates the work of a leader, and one would not argue with Berreby's assertion that "science's more accurate picture of the brain is well worth getting to know". The more you can influence people in your organization, the better you succeed as a leader. Depending on whom you interact with, the notion of a dominant, strong and less emotional being to the cool, suave and refreshing figure may just be a dynamic and responsive take on leadership.

Biology may just as well play a role in the leader's ability to understand behavior and adapt communication accordingly, with the end goal of influencing actions. We hear leaders who "talk the talk, and walk the walk"; they begin with a convincing narrative. The brain likes a good story, says Berreby (2010). This author believes storytelling helps the brain keep things 
together, fusing different processes into what he describes as a coherent experience. Organizational employees relate to stories, witty but meaningful to their experiences. Good leaders tell good stories. Recently, a charismatic and respected leader shared a piece of poetry to make a point. The piece was enough on its own to get the point across. It was a poem by British Nobel laureate Rudyard Kipling (1910). The first paragraph reads:

"If you can keep your head when all about you are losing theirs and blaming it on you; If you can trust yourself when all men doubt you, But make allowance for their doubting too. If you can wait and not be tired by waiting,

Or being lied about, don't deal in lies, Or being hated, don't give way to hating, And yet don't look too good, nor talk too wise...."

It was only a piece of poetry, but how impactful was that? The impact was simply a work of influence. Leadership is influence, nothing more, nothing less. Isn't that the way John C. Maxwell described it? Influence through art, the art of poetry. Some leaders have mastered the art of appealing to the employee's curiosity, whether through inducing laughter, or appealing to the unconscious mind through storytelling or artistic forms of connections such as poetry. As complex as the brain is, it relates to and connects with such narratives. What about the leader who is not cut out for storytelling? Do you learn to do this? Are some people just born to be funny? This obviously adds to the ongoing debate on what the brain is genetically predisposed to, or interactively learns on planet earth. Not every leader has mastered communicating through art; perhaps biology has a role to play in this.

In a recent article published on LinkedIn, Tyagarajan (2017) boldly said: “... curiosity is the single most important leadership quality I look for when promoting internally or hiring from the outside." He suggested that skills and education are not enough to accurately predict someone's full potential. He further proposes that if you want Innovation, you should hire curios people.

In line with the focus of this article, the question then becomes - how do you identify curiosity in people? Do they acquire these traits over time from work experience, or does biology and the way the human brain is wired play a role in this? Attempts at understanding the linkages between business, biology and brain science continue albeit seen through various channels. The Imperial College of Science and Technology launched a BSc. In Biological Sciences with Management. The college proclaims that, "Biological Sciences at Imperial aims to understand the behavior of living systems from the level of cells up to whole organisms and ecosystems."

The interconnectedness between biology, business and brain science will continue to dominate research circles through understanding individual and organizational behavior, how leaders lead and hire. Countless lessons from business on successful leadership have told of "leaders as change agents;" connecting innovation and creativity to an overall vision. At the end of the day, it's the same cliché; that leaders are born, not made (depending on what end of the compass you stand). Leaders need to have the desire and drive to lead. Some of these traits correlate with individual personality, communication, excitement and views on life.

\section{BRAIN SCIENCE FASCINATIONS}

Historically the brain has projected an aura of arcane mystery. Struck by its complexity and power, pioneering neurophysiologist and Nobel laureate Sir Charles Sherrington referred to it as an "Enchanted Loom." About the brain Sherrington (1942) poetically mused, "The great topmost sheet of the mass, that where hardly a light had twinkled or moved, becomes now a sparkling field of rhythmic flashing points with trains of traveling sparks hurrying hither and 
thither. The brain is waking and with it, the mind is returning. It is as if the Milky Way entered upon some cosmic dance. Swiftly the head mass becomes an enchanted loom where millions of flashing shuttles weave a dissolving pattern, always a meaningful pattern though never an abiding one; a shifting harmony of sub patterns."

Attempting to comprehend the complexity of the brain has become something of a cottage industry in itself. Efforts to understand the brain's intricacy have led to a variety of additional comparative analogies including: mechanical clockworks, computers, and a Swiss Army knife. According to science journalist Judith Horstman, even these elementary explanatory attempts break down under scrutiny. "But now it seems that's a bit too simplistic too. As we learn more, it has become clear that how well the brain works depends on how these modules are linked together to perform as circuits. The brain is, in fact, more like the Internet." (Horstman, 2010).

A virtual explosion of knowledge related to apprehending the brain has occurred over the past twenty-years. Fostered by billions of dollars of significant research investments by both governmental bodies and the private sector, many new discoveries about the structure and function of the human brain have been unearthed. Significant among the research breakthroughs are:

- Neuroplasticity

- Extent of unconscious processing

- Mirror neurons

- Separate pleasure and pain networks in the brain

Up until recently, scientists believed the brain had only limited capacity to rewire itself. Many studies now show that the brain is almost continually changing itself because of the inputs it receives. This ability seems to remain with us throughout our lifespan. Neuroplasticity is the name given to the remarkable flexibility of the brain to reform and reorganize itself as a direct consequence of learning or damage. A closely related discovery has been that of neurogenesis or the capacity of some of the brain's neurons associated with memory and smell to selfregenerate.

Neuroscientist David Eagleman has investigated the role of the unconscious brain processing. He notes, "The first thing we learn from studying our own circuitry is a simple lesson: most of what we do and think and feel is not under our conscious control." (Eagleman, 2011). Some estimates by neuroscientists put the extent of the brain's unconscious processing at $90 \%$. For example, from the over five million bits of information from our senses arriving in the brain every second only a tiny percentage make it to consciousness. "Neuroscientist Kevin Ochsner estimates that humans act according to habit $70-90 \%$ of the time, and are guided by deliberate mindful actions only $10 \%-30 \%$ of the time." (Hills, 2016).

Italian neuroscientists accidentally made a momentous discovery about brain function in the 1990s while working with rhesus monkeys with brain-implanted electrodes. The researchers noted that the same group of neurons in the monkey's brains became active not only when they performed an action themselves but also when the monkeys observed the same action in others. Psychologist V. S. Ramachandran has commented on the perceived value of the discovery of this particular class of brain cells, called mirror neurons. "I predict that mirror neurons will do for psychology what DNA did for biology: they will provide a unifying framework and help explain a host of mental abilities that have hitherto remained mysterious in inaccessible to experiments." (Hickok, 2014). 
Researchers have discovered that the neural circuits associated with the experiences of pleasure and pain are distinctly separated in the brain. Perceived sensations of pleasure and pain have also been shown to be mediated by different groupings of neurons. Each of the circuits employs a different type of neurotransmitter or substance that carries an electro/chemical signal from one nerve cell to another. Additionally, scientists have learned that the brain uses these same circuits to process both physical and social sensations. For example, the negative feeling engendered by harsh words from your boss can give you a headache just like hitting your finger with a hammer might. Neuroscientists have also determined that the brain has difficulty differentiating something that is vividly imagined from something that is actually experienced.

Yet, in the main, the brain still contains much unexplored territory. British neuroscientist Dean Burnett has formulated the dilemma of the uncharted areas of the brain very succinctly. "In many ways, the brain is a victim of its own success; it's evolved over millions of years to reach this current level of complexity, but as a result it as accrued a great deal of junk, like a hard drive riddled with old soft-ware programs and obsolete downloads that interrupt basic processes, like those cursed pop-ups offering you discount cosmetics from long-defunct websites when all you're trying to do is read an email." (Burnett, 2016).

\section{Biology-Business Bonds}

\section{BEYOND ENTICEMENTS, PROMISES AND FASCINATIONS}

- Biomimicry. Popularized by applied science writer Janine Benyus, biomimicry attempts to apply lessons learned from nature to solve practical human problems. The field is defined by the Biomimicry Institute as, "An approach to innovation that seeks sustainable solutions to human challenges by emulating time-tested patterns and strategies." (Biomimicry Institute, 2017). Examples of business applications are: the development of a commercial adhesive that works underwater from studying how mussels attach themselves to rocks, employing the shape of a diving bird's beak to mitigate shock waves on a high-speed train, and a spread frequency echolocation device inspired by the sonar of dolphins.

- Ecosystems. Writing in their book The Keystone Advantage subtitled What the New Dynamics of Business Ecosystems Mean for Strategy, Innovation, and Sustainability business strategists Marco Iansiti and Roy Levien propose that the biological concept of ecosystems has broad applicability to business. They note, "Like business networks, biological ecosystems are characterized by a large number of loosely interconnected participants who depend on each other for their mutual effectiveness and survival." (Iansiti and Levien, 2004). Townsend (2009) echoes this sentiment, "The advent of business ecology simply represents the reintroduction of ecological, science-based thinking back into the human enterprise."

- Biology Influenced Business Strategy. "The thoughtful application of biological concepts offers considerable promise to the business strategist. For example, by using biological systems as a reference point for thinking about organizational birth, growth and decline, business strategies can be thought of as having a life cycle of their own. "That is, strategies typically have origins, shakeout, refinement, productivity, decline, and an end-of-effectiveness stage." (Forbes, 2013).

\section{Biology-Brain Associations}

- Myth of multi-tasking. Recent research does not confirm the performance benefits of multi-tasking. What happens is a serial, rapid switching between individual tasks as opposed to handling many tasks simultaneously. Attempts to resume work after a dropped task result in time delays and comprehension losses accumulated during the 
recovery. Neuropsychiatrist Richard Restak, who studies the means for improving the brain's performance, has noted the cognitive restrictions imposed when attempting to multitask, "A 'neural network' within the frontal lobes acts as a 'central bottleneck of information processing that severely limits our ability to multitask." (Restak, 2009).

- Three embodied brains. Besides the brain residing in the skull, two other areas in the body contain significant brain tissue, the gut and the heart. The enteric nervous system is an independent site of neural integration that controls the digestive process. Over 100 million nerve cells constitute this system, which has been called "the second brain." According to gastroenterologist Michael Gershon, "The enteric nervous system is thus not a slave of the brain but a contrarian, independent spirit in the nervous organization of the body. It is a rebel, the only element of the peripheral nervous system that can elect not to do the bidding of the brain or spinal cord." (Gershon, 1998). The heart has also been shown to have its own nervous system. "In 1991, the year the HeartMath Institute was established; pioneer neuro-cardiologist Dr. J. Andrew Armour introduced the term 'heart brain.' He found that the heart possessed its own complex intrinsic nervous system that acts as a brain and functions independently from the brain in the head." (Childre, Martin, Rozman and McCraty, 2016). The heart has also been determined to generate a magnetic field more than 100 times stronger than that produced by the brain.

- Stress Mediation. University of California at Los Angeles clinical professor Dan Siegel is one of the world's leading authorities on stress. Siegel is a leading proponent of the field of Interpersonal Neurobiology. He believes that overwhelming events can disrupt normal human functioning via activation of the sympathetic nervous system. "An interpersonal neurobiology view of this finding is that the body's normal responses to stress are not released, prolonging acute reactions that then become chronically maintained stances of vigilance." (Siegel, 2012). In other words, the body remains in a constant state of destructive physical and emotional alert maintained by a flow of hormones and neurotransmitters from the brain. Siegel suggests a number of physical and mental activities, including meditation, as a means for stress reduction.

\section{Business-Brain Connections}

- Brain as Chief Executive Officer. The prefrontal cortex of the brain has become a metaphor for the primary executive function in business, the CEO or Chief Executive Officer. Brain researcher Eliezer Sternberg makes the case this way, "In cognitive neuroscience, the term 'executive function' is used to describe the highest-order functions of the brain, including planning, decision-making, the control of attention, and self-monitoring. Executive function is to the brain as a CEO is to a company. It endows us with the ability to broadly control the way we think and act." (Sternberg, 2015).

- Business and the Whole Brain. Brain researchers Ned Herrmann and Ann HerrmannNedhi have extensively explored the connection between the brain and individual and organizational performance. Using the concept of thinking styles derived from a study of the physical anatomy of the brain, the Herrmann's have correlated four basic thinking styles with specific management characteristics. In a study of 9,300 Chief Executive Officers representing a variety of industries from 76 countries, it was found that CEOs had the strongest preference for visionary thinking and were very strong in the remaining three styles: Analyzer, Organizer, and Personalizer. (Herrmann and Herrmann-Nedhi, 2015).

- System 1 and System 2 Thinking. Developed by Nobel Prize in Economics winning psychologist Daniel Kahneman, this concept attempts to categorize how the human mind makes decisions and judgments. This idea challenges the typical rational mindset 
by which business managers are presumed to make decisions. "System 1 operates automatically and quickly, with little or no effort and no sense of voluntary control. System 2 allocates attention to the effortful mental activities that demand it, including complex computations. The operations of System 2 are often associated with the subjective experience of agency, choice, and concentration." (Kahneman, 2011).

- New business subfields. One consequence of the new focus on brain science has been the creation of a_whole series of business sub-disciplines intimately connected with neuroscience. "These specialties include, among others: neurofinance, behavioral economics, neuromarketing, and neuroleadership. Neurofinance is concerned with studying the nature of the mental processes engaged in obtaining, processing, and utilizing information related to financial decision-making. Behavioral economics focusses on the identification and consequences of decision choices on individuals and organizations particularly in relationship to allocation of resources. Neuromarketing studies the brain's responses to marketing stimuli. Neuroleadership applies the findings of relevant brain research to the field of leadership." (Forbes, 2016).

- Flow as Peak Performance. Researchers concerned with human performance have begun to establish the fact that superior performance in a wide variety of settings is related to an individual being able to closely match the demands of a task with the capacities they have previously developed. The coincidence of the two factors results in an internal mind-body state that fosters peak performance called "flow" or "being-inthe-zone. "Thanks to decades of solid research by neuroscientists, more and more leaders are coming to the realization that reducing distractions, discouraging multitasking, and encouraging mindfulness in the workplace are putting their employees on the path to the most satisfying and productive form of focus: flow." (Fabritius and Hagemann, 2017).

\section{POSSIBILITIES FOR UTOPIA OR DYSTOPIA}

One of the pioneers in the field of Behavioral Economics, eminent psychologist Amos Tversky, is quoted as having said, "A part of good science is to see what everyone else can see but think what no one else has ever said." (Lewis, 2017). This section will look into the future at two possible as of yet unsaid scenarios related to the biology, business and brain science convergence. The first will offer a "best case" or utopian prediction. The second will describe a more "worst case" or dystopian picture. A word of warning to keep in mind as you proceed. Writer and futurist William Gibson has allegedly stated about the prospect of imminent events, "The future has already arrived. It's just not evenly distributed."

\section{The optimistic scenario}

Klaus Schwab, the founder of the annual Davos World Economic Forums, is a strong proponent of a bright convergent future. He believes the world is already in the early stages of a fourth industrial revolution. In Schwab's schema of change, the first revolution occurring from 1760 to 1840 was propelled by the invention of the steam engine and the rapid growth of railroads. The second revolution, he concludes, happened during the final stages of the nineteenth century and into the early to middle years of the twentieth. This was an era dominated by electrification and mass production. In this period, large-scale technological and social change was punctuated via developments associated with two world wars.

The third industrial revolution was traced to 1960 and its deep association with computers, semiconductors, and the internet. The fourth revolution, Schwab avers, is just now getting underway and will be closely associated with pervasive sensors, a mobile internet, artificial intelligence, and machine learning. He has also noted, "The convergence of the physical, digital and biological worlds that is at the heart of the fourth industrial revolution offer significant 
opportunities for the world to achieve huge gains in resource use and efficiency." (Schwab, 2016)

Alec Ross author of The Industries of the Future offers a parallel, related, affirmative perspective. Ross writes, "This book explores the industries that will drive the next 20 years of change to our economies and societies, Its chapters are built around key industries of the future-robotics, advanced life sciences, the code-ification of money, cybersecurity, and big data-as well as the geopolitical, cultural, and generational contexts out of which they are emerging." (Ross, 2016).

\section{The pessimistic scenario}

In this darker view of the convergent future, the world will become a more complex, hostile and dangerous place for humans. Our brains will be unable to keep pace with the accelerating pace of change and will become overloaded from coping with the vast amount of information available. Consequently, stress-related diseases will reach epidemic proportions.

The consumer equation will have changed from the past; services and the consumption of experiences will have become dominant over physical goods. About this change, psychologist and behavioral economist Dan Ariely notes, "From this industrial era point of view, capitalism and labor were based on a simple equation: individuals needed and wanted stuff; companies made and shipped the stuff people wanted, laborers worked at dismal jobs for long hours so they could buy stuff. Workers were assumed to view work as unpleasant, but the reward was assumed to be so important (a paycheck) that it was worth suffering through to achieve and exchange it for stuff." (Ariely, 2016).

Machine intelligence will surpass human intelligence with negative consequences. The algorithms of artificial intelligence, coupled with robotics, will have become ubiquitous and displaced much of the workforce of nations. Even the so-called creative professions will be under attack by the onslaught of algorithms. Some biologists already think of us in algorithmic terms. Israeli historian Yuval Harari notes, "Over the last few decades biologists have reached the firm conclusion that the man pressing the buttons and drinking the tea is also an algorithm. A much more complicated algorithm than the vending machine, no doubt, but still an algorithm." (Harari, 2017).

The wealth gap will have increased. Having not learned our lessons from the financial crises of the 1980s we find them repeated in the 2020s. Economic peaks and valleys will become more unpredictable and disastrous. Greed, stress and brain chemicals will further victimize our biology. Physiologist and former Wall Street trader John Coates has previously raised the specter of this downside possibility. "Indeed, under the influence of pathologically elevated hormones, the trading community at the peak of a bubble or the pit of a crash may effectively become a clinical population. In this condition business may become price and interest-rate insensitive, and contribute to the violence and intractability of runaway markets to what Nassim Taleb has called 'Black Swan' events.” (Coates, 2012)

\section{SUMMATION}

Words like biology, business, and brain science tend to evoke different thoughts and feelings in each of us. As a consequence of reading this article, our hope as authors is that you will now think differently about them both singly and in combination. MacArthur Foundation genius award winner, neurobiologist and primatologist, Robert Sapolsky has commented on the ability of words to profoundly influence behavior. He has noted, "Words have power. They can 
save, cure, uplift, devastate, deflate, and kill. And, unconscious priming with words influences pro-and antisocial behavior." (Sapolsky, 2017).

Which of the described future scenarios, or yet something else completely unanticipated, plays out will have to wait the test of time. The rapidly growing edge of neuroscience brings us faceto-face with the whole idea of our species limits and what it means to be human. Are we to live as neuro-augmented beings or wind up being subservient to super intelligent machines? John Donoghue of the Brown Institute for Brain Sciences has given this question considerable thought. He notes, "The most speculative piece of the emerging neurotechnology revolution is its effect on what it means to be a member of our species. If we could replicate the most cherished and specialized human brain functions, we could be able to augment our abilities." (Donoghue, 2015).

Additionally, the effects of culture on an integration of biology, business and brain science cannot be discounted. Respected social psychologists Thomas Gilovich and Lee Ross have commented, "We find it hard to appreciate that it is our culture that much of the world regards as strange. In fact, anthropologist Joe Heinrich and his colleagues have coined the acronym WEIRD (for Western, educated, industrialized, rich and democratic) to alert us to the features of our culture that distinguish us from much of the rest of the world." (Gilovich and Ross, 2015). Different, however, is not necessarily better. It seems that, in many respects, warranted or not, the West has assumed the mantle of desired economic model, resource controller and academic intellectual leadership. The ancient adage of, "them that has the gold makes the rules" seem to be particularly appropriate in this regard.

It is indeed a moot question as to how much of what we see is biased by what we believe. The latest findings in brain science appear to be telling us that unconscious processes influence many more of our perceptions of reality than we have heretofore realized. The perspective of the erudite, affluent, and English-speaking aspect of Western hemisphere culture has also come to dominate much of our thinking about biology, business and brain science. This social viewpoint would include WEIRD thoughts about what might be classified as strange attractors. The notion of strange attractors itself does, at first glance, seem to be somewhat outlandish and extraordinary. It is challenging to grasp the idea of the interaction of invisible forces that produce islands of stability in a turbulent world. Another, perhaps more vivid metaphorical image for understanding strange attractors is that of a set of forces produced by magnets. Two magnets placed under a piece of paper containing iron filings produce a visual picture of the energies involved. The filings align themselves around the poles of the magnets. The magnets generate "interacting fields that pull or attract and alter the course of energy flows, which result in patterns from what looks for most of the process to be chaos, until suddenly a clear pattern emerges." (McMaster, 2016).

Up until just recently the notion that a series of numbers strung together in long arithmetic sequences and formulas and fed into a computer could have a profound impact on people's lives appeared to be particularly bizarre. Then along came computer operating systems, numerically controlled machines, and processor programs that regulated banking, the highspeed trading of stocks, and global financial transactions. It has been suggested that, presently, "We live in the age of algorithms. Only a generation or two ago, mentioning the algorithm would have drawn a blank from most people, algorithms are in every nook and cranny of civilization." (Domingos, 2015).

Although biology and geography may not be destiny, they certainly will be powerful forces that help shape the future. About the formative role of the past, economic commentator Said 
Dawlabani has noted, "The theoretical physicists and the math geniuses that were behind the creation of the Wall Street algorithms that caused the financial crises were attracted there mainly because of the pay, not because of their conviction in serving humanity's best interests. Had these scientists gone into fields that properly utilized their talents, such as the knowledgeeconomy or rocket science at NASA, the economic landscape today would have looked completely different." (Dawlabani, 2013).

Complexity, along with fear, uncertainty, and doubt has been identified as one of the major maladies of the current age. Former businessman-trader and professor of risk engineering Nicholas Taleb has noted, "Complex systems are full of interdependencies-hard to detectand nonlinear responses. 'Nonlinear' means that when you double the dose of, say, a medication, or when you double the number of employees in a factory you don't get twice the initial effect, but rather a lot more or a lot less." (Taleb, 2012). This nonlinear unpredictability is at the heart-of-the matter of forecasting the future. Thus, an actual event might bear very little resemblance to the initial forecast about it, the variance being very sensitive to the original conditions existing at the time of the prediction.

The common point of integration between biology, business and brain science is that they all are intelligent complex adaptive systems concerned with human beings. The task of attempting to understand the multifaceted connections and interdependencies regarding biology, business and brain science has been both perplexing and rewarding. In the authors of this paper's struggle to make sense of the biology, business and brain science distinctions, we were reminded of the prescient words of authors Steven Kotler and Jamie Wheal. "There's one final caveat worth keeping in mind. Namely, there is no escaping the human condition. We're born, we die, and figuring out the in between can be brutal." (Kotler and Wheal, 2017). Moreover, the challenge for all of us is that it's in the in-between where we will be spending most of our lives.

\section{References}

Ariely, D. (2016). Payoff. Simon and Schuster, 29.

Biomimicry Institute (2017).What is biomimicry. Retrieved April 10, 2017, from http://biomimicry.org/what-isbiomimicry/

Burnett, D. (2016). Idiot Brain. Norton, 3.

Childre, D., Martin, H., Rozman, D. and McCraty, R. (2016). Heart Intelligence. Heart Math, 28-29.

Cialdini, R. (2016). Pre-Suasion. New York: Simon \& Schuster,15.

Coates, J. (2012), The Hour Between Dog and Wolf. Penguin Books, 267.

DeVito, D., Shamberg, M., Sher, S., Lyon, G., (Producers), \& Niccol, A. (Director). (1997). Gattaca [Motion Picture]. Country of Origin: USA, Studio, Columbia

Domingos, P. (2015). The Master Algorithm: How the Quest for the Ultimate Machine Will Remake Our Worlds. Basic Books, 1.

Donogue, J. (2015). Neurotechnology. In The Future of the Brain. Marcus, G. and Freeman, J. (eds.). Princeton University Press, 231.

Eagleman, D. (2010). Incognito. Pantheon, 4.

Fabritius, F. and Hagemann, H. (2017). The Leading Brain. Tarcher Perigee, 107.

Forbes, R. (2013). An Ecological Approach to Organizational Strategy. American Institute of Business Psychology Newsletter, June, 2013, 1.

Forbes, R. (2016). So, What Does Neuroscience Have to Do with Business Psychology? American Institute of Business Psychology Newsletter, January, 2016, 1.

Gershon, M. (1998). The Second Brain. Harper, 11. 
Gilovich, T. and Ross, L. (2015). The Wisest One in the Room, Free Press, 161.

Gleick, J. (1987). Chaos. Viking.

Harari, Y. (2017). Homo Deus. Harper Collins, 85.

Herrmann, N. and Herrmann-Nedhi, A. (2015). The Whole Brain Business Book, 2nd Ed. McGraw-Hill, 274. Hickok, G. The Myth of Mirror Neurons W. W. Norton, 1.

Hills, J. (2016). Brain-Savvy Business, Head Heart+Brain, 261.

Horstman, J. (2010). The Scientific American Brave New Brain, 9.

Iansiti, M. and Levien, R. (2004). The Keystone Advantage. Harvard Business School Press, 8.

Kilman, R. (2001). Quantum Organizations. Davies-Black, 46.

Kipling, R. (1910). IF. Retrieved June 18, 2017, from https://en.wikipedia.org/wiki/If\%E2\%80\%94

Kotler, S. and Wheal, J. (2017). Stealing Fire. Harper Collins, 216.

Leaders are Born, Not Made. (2012, February 03). Retrieved June 18, 2017, from

https://colleensharen.wordpress.com/2012/02/09/leaders-are-born-not-made/

Lewis, M. (2017). The Undoing Project. Norton, 345.

Maxwell, J. (2014). The 21 irrefutable laws of leadership: follow them and people will follow you. Thomas Nelson.

McMaster, M. (2016). What is Organizational Intelligence. McMaster, 18.

Restak, R. (2009). Think Smart. New York: Penguin, 201.

Ross, A. (2016). The Industries of the Future, 12.

Sapolsky, R. (2017). Behave. New York: Penguin, 92.

Sherrington, C. (1942). Man on his nature. Cambridge University Press, 178.

Schwab, K. (2016). The Fourth Industrial Revolution. World Economic Forum, 64.

Siegel, D. (2012). Pocket Guide to Interpersonal Neurobiology. W.W. Norton, 39-2.

Stephens, Z., Lee, S., Faghri, F., Campbell, R., Zhai, C., Efron, M., et al. (2015). Big Data: Astronomical or Genomical? PLoS Biol 13(7).

Sternberg, E. (2015). Neurologic. Pantheon, 58.

Taleb, N. (2012). Antifragile. Random House, 7. The Biology of Leadership: Giving the Brain a Seat at the Table. (n.d.). Retrieved June 18, 2017, from https://www.kornferry.com/institute/50-the-biology-of-leadership-givingthe-brain-a-seat-at-the-table

Townsend, A, (2009). Business Ecology. Schiffer, 90.

Tyagarajan Tiger, Want Innovation? Hire Curious People. Retrieved June 18, 2017, fromhttps://www.linkedin.com/pulse/want-innovation-hire-curious-people-tiger-nv-tyagarajan 